thicir bodies. If this is so, the sooner this crroneous idea is remored the better.

1 Lancet, November 7th, 1914, p. 1084

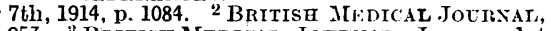
December 5th, 1914, p. 953. '3 British Medical Jocknal, January ls

\section{SOME PRACTICAL HINTS}

\section{ON THE LOCALIZATION OF BULLETS AND} SHELL FRAGMENTS.

By FRANCIS HERNAMAN-JOHNSON, M.D.,

MIDICAL OFFICER IN CIIARGE $X$ RAT AND FLECTRICAL DEPAIRTMENT, Aij) LE(TCRER ON MILITARY RADIOLOGY, CAMBRIDGE HOSPITAL,
ALDERSHOT.

Sixce the publication of my short note on a method of bullet localization, ${ }^{1}$ I have received numerous letters asking for further information on the subject, and referring to various practical difficulties met with in the course of sucl work. These difficulties are mainly the result of two causes: inability to get the limbs into the position lesired, and the presence of large suppurating wounds. Pain may prevent a limb being flattened out on the couch. top, preparatory to obtaining the vertical line. For example, it may be possible to straighten a knee only to within 30 to 40 degrees of full cxtension. T'lie limb may, however, be held in position and two marlss, one beneatl the other, obtained; these will form a perfectly goorl guide to the surgeon, provided that the knee be operated on a the same angle. The lateral marks are, of course, obtained as usual.

Again, the patient's wounds or general condition may prevent him from being rolled on to his side so as to get lateral markings. This difficulty may be got over by using a second tube in an upright stand, so arranged that its normal ray is at right angles to that of the one beneath the concl. The procedure is exactly as before, the only inconronience being that the tube is not so readily nanœurred into position as in the case of one resting on in carriage with universal movement (Fig. 1).

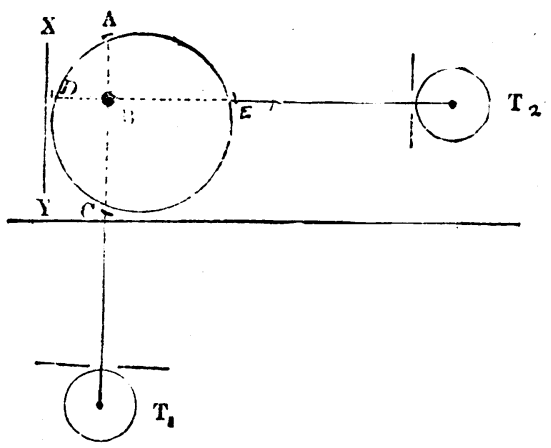

Fig. 1.-T, Tute under couch; B, bullet; $A$ and $c$, first markings $T 2$, tube in adjustable stand, with diaphragm: I) and $\mathrm{T}$, cross markings ; $X \mathrm{Y}$, position of screen while obtaining the latter.

The use of a second tube has, howerer, one small advantage. The "cross markings" are made withont the limb having been moved. When a patient is shifted so as to obtain a lateral view, care should be taken that the muscles of the limb are not thrown into action. If a bullet is lodged in the belly of a muscle, it may more relatively to the slin mark when the musele contracts. Therefore the patient should always be instructed to remain absolutely passive; he must be rolled over, not allowed to turn over limself.

Patients with large suppurating wounds near the parts where the skiagrams must be taken may be prepared by having the limb wrapped in sterile gauze, covered by a layer of thin waterproof material, the whole being secured by a well-fitting bandage. 'Localization marks are made on the banclage. Afterwards the bandage is snipped with scissors at the points indicated, and nitrate of silver marks are made on the skin. It may be that one of the markings is directly over an open wound. The surgeon will thien hare to be content with three points only.

'The discharge from some of these wounds is so copious that unless very stringent precautions are taken some of: it is apt to escape. The screen, couch, and localizer are soiled, and infection may be transferred to other cases. A localizer made entirely of metal is undoubtedly an advantage, as it can be boiled after each case. If , in addi. tion, a square of sterilized waterproof is spread on tho conch, and another is interposed between the screen and the limb, the precautions are complete.

In numerous instances localization can only be carried out properly under an anaesthetic. By arrangement with the surgeon and the anaesthetist the patient is anaes. thetized on the $x$-ray couch, and the operation is performed immediately afterwards. As the localization can be carried out before surgical anaesthesia has becn reached, this procedure does not prolong the operation. It is necessary to have the room in darkness only for a few seconds at a time, but if the anaesthetist is troubled by this, a fluoroscope may be used in all but very difficult cases.

Those cases in which bullets or shell fragments haro lodged in the neighbourhood of the hip-joints, pelvis, and shoulder girdle, require special consideration. Where powerful apparatus is at hand, where the bullet is of full size and the patient thin, cross markings may bo obtained in these regions, but they cannot be counted on as a rule. The vertical line, on the other hand, can always be ascertained, and various means are employed to ascertain the distance of the bullet below the surface along this line.

In the region of the hip and shoulder stercoscopy is very valuable. The vertical line of the bullet should, however, be found in the usual manner. The diaphragnt is then opened, and the plates taken by moving the tube $3 \mathrm{~cm}$. on either side of the original position. If this plan is followed, the true vertical relationship of bullet and bony landmarks will be seen in the stereoscope. For instance, if the bullet appears to be directly orer the middle of tho acetabulum, this repre. sents what will ac tually be found at operation. Some peoplo have an idea that because a stereoscopic image gives an appearance of solidity therefore the exact position of the tube does not matter. That this is a mistaken view very little thonght wil show. Suppose, for instance, we desire to centre an $x$-ray tubo which has no plum met over any particular part of the body. It is necessary to get into a position from which one can look directly down on the desired spot, as it is not possible to be sure of the correct cen tering of the bulb 1 rom any other view-point.

Where cross maris ings cannot be : ob tained, and where it is desired to localize withont the necessity of taking plates, or to gain information additional to what is given by the stercoscope, some modification of the well-known method of triangula. tion must be cm ployed. Of such modifications thore are

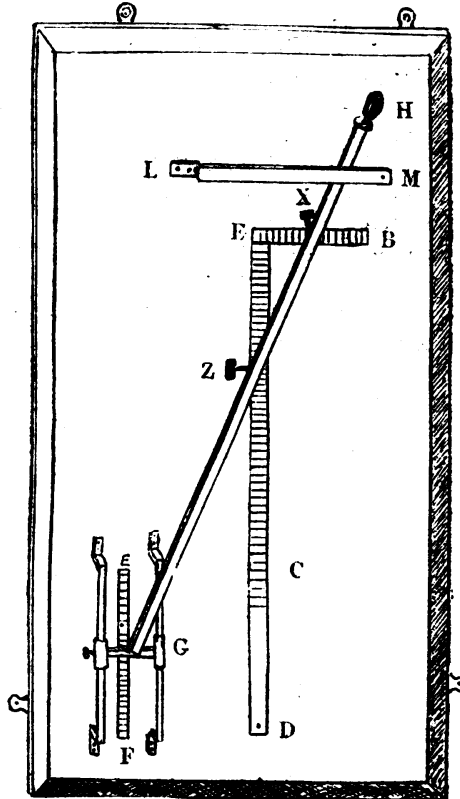

1ig. $2 .-\Lambda$ board, $36 \mathrm{in}$. high, $18 \mathrm{in.}$ wide, and $\frac{1}{2}$ in. in thickness, is screwed to the wall of the $x$-ray room. On it, in the position shown, is drawn a rertical scale, 26 in. in length. Ot distance portion E C represents the the top of conch. The anticathode and left is a parallel scale, $\mathrm{F}, 10$ in 10 the $\mathbf{E} B$ is a scale running to the risht. perpendicular to $E \mathrm{D}$; it is 3 in. lons. $\mathrm{G} H$ is a rigid arm, $32 \mathrm{in}$. long, pivote $\mathrm{i}$ vertically between $E$ and $F$, and clamped in any desired position. The freely excent when clauped by screw at $M$. at $G$. The pivot $G$ can be moved ever is steadied at the tol by the

several, and the choice between them must be largely a matter of personal preference. For my own us I havo designed a simple apparatus which I call a " depth indicator," shown in the appended rough diagram matic skotch (Fig 2), which, howerer, makes no pretensions to exact scale.

'To ascerrtain the depth at which a builet iies, the tube is, as usual, manoureed into a position rertically below the 
bullet, and the position of the latter marked on the skin by means of the ring localizer, which for this purpose should be provided witl two wires crossing in its centre at right angles, as great accuracy is necessary. The diaphragm is thel fully opened and the tube moved a distance of $5 \mathrm{in}$. If the bullet is at any depth, its image, of course, moves in the opposite direction to the tube. The new position is marked on the skin by the ring localizer, care beirg taken that the same part of the bullet shadow is used as a guide in each case. The distance between these two points is measured. Next, the distance between the upper surface of the patient's body and the couch top must be found. The overhead compressor attachment supplied with the Ironside Bruce couch by some firms can be readily utilized for this purpose; otherwise some simple form of calipers must be used, or an arrangement such as used for measuring the height of recruits can be employed. Finally, the second dot should be rubbed out, the tube replaced in the vertical position, and the mark made under the body by the localizer in the usual way.

Suppose the measurement between the two surface marks is $1 \mathrm{in}$. The sliding pointer $\mathrm{X}$ is moved along E B to the right for that distance and clamped. Suppose, further, that the measurement from couch top to surface of patient is $6 \mathrm{in.} ; \mathrm{G}$ is moved that distance belorv $\mathrm{C}$ and clamped (that is, $\mathbf{E} \mathbf{C}+6 \mathrm{in}$. = the total distance between target and upper surface of patient). The lever $\mathrm{GH}$, which has been resting against $\mathrm{M}$, is now brought to the left till it is stopped by $\mathrm{X}$. The pointer $\mathrm{Z}$ is moved downward till it meets the lever, and the distance $\mathrm{E} \mathrm{Z}$ is the vertical depth of the bullet.

The above instrument is designed to enable the depth of a bullet to be gauged with a maximum of convenience, speed and accuracy. The principle may, however, be cmployed in a home-made fashion as follows:

Paste on to the wall at a convenient height a sheet of white paper of suitable dimensions. Draw scales as described Mark off $\mathrm{E} C$ to the length of the couch you work with and Mark off E C to the length of the couch you work with and
number E F in inches and quarters from above downwards. number $\mathbf{E}$ in inches and quarters from above downwards. place its lower and left-hand corner against the proper scale place its lower and left-hand corner against the proper scale mark, and, holding it in place by the left hand, bring the upper right-hand edge to the required distance along $\mathrm{E} B$. Then read
off the distance $\mathrm{E} \mathrm{Z}$. The rule must be kept flat against the off the distance $\mathrm{E} \mathrm{Z}$. The rule must be kept flat against the
wall, and one must see that the lower end is still in place before making the final reading. Be sure to interpret the distance E X liberally, so as not to underestimate the depth.

The above method of calculating the position of a bullet is recommended only where cross markings cannot be readily obtained. The latter are greatly preferred by most surgeons, as they serve as guides after the vertical relationships have been disturbed by the progress of the operation. In the case of limbs it is a good plan to make corresponding marks on the sound side. This is readily done by means of the band of flexible metal referred to in my previous paper. Where cross markings are impossible, as on the lower abdomen, we should never neglect to mark the patient below as well as above. In addition, tho surface on which the incision is to be made should bo marked by a cross consisting of lines 4 to 5 in. in length, cutting each other at right angles, the point of intersection being the original dot. By this precantion the position of the latter can be judged even after considerable "sagging" has taken place; and by the aid of the opposing dot the line in which the bullet lies can be reconstructed. It has been objected that it is diffi. cult to make a mark beneath a patient by means of the ring localizer; but, if a little care is used, the lattcr can be quite easily held in place while the paticnt is tilted sufficiently for the purpose. An all-metal ring localizer, sterilizable by boiling, is made by Messis. W. Watson and Sons, Great Portland Street, W. It has cross wires, and also an ariangement for making a mark beneath a patient's body without disturbing him. They are also prepared to supply to order for immediate delivery "wall-diagrams," and have in preparation a mechanical device based on the principles shown in Fig. 2.

Many operations for the removal of bullets are difficult, cven when they have been clearly seen on the screen, and properly localized by cross lines. Where bullets are lodged in the fleshy parts of limbs screen localizing is usually the only method of value. By this I mean that no additional information of value can be obtained from plates. But in the case of a bullet which has lodged near a joint or entered a bone, the whole resources of the radiographic art should be placed at the surgeon's disposal. I have seen a surgeon of much experience fail to extract a rifle bullet which had lodged in the astragalus, although he had a lateral radiograph and exact cross markings on the skin. In this case stereoscopy might, perhaps, have turned failure into success.

As to the relative value of stereoscopic views and those taken at right angles to each other, whenever the latter can be properly obtained they are of more assistance than the former. The vertical line of the bullet must be first found by the screen. The bullet image on the plate can then be fitted over the skin marks if desired.

If for any reason it is not practicable to talse photographs where in reality they should be taken, the surgeon's presence at the screen localization is desirable. It is very important that the operator should understand the principles on which his colleague works. This would often avoid the making of impossible requests. On the other hand, the radiographer ought certainly to attend operations. He will then realize better the practical problems which have to be confronted, and perhaps be able to devise further means of help.

If the radiographer values his reputation, he will endeavour himself to do all localizations. Lay assistants may often be trusted to turn out good plates, but prognostications as to the position of bullets are quickly put to tho test of surgery, and when failure occurs, as sometimes it will, it is comforting to have the conviction-not always shared by the surgeon! - that no fault can be laid at the door of the $x$-ray department.

Referince.
${ }^{1}$ British Medical Journal, October 31st, 1914.

\section{A RAPID METHOD OF LOCALIZATION BY} X RAYS.

By K. W. MACKENZIE, M.R.EDIN., Lieutenant, R.A.M.C.,

Late captain, indian medical service.

(No. 11 General Hospital, British Expeditionary Force.)

In order to supply the need felt for a means of localizing foreign bodies which could be applied during the screening of a case, and without the loss of time involved in changing the tube to the overhead position and developing a plate for the Mackenzie Davidson method, the following method was devised, with the assistance of Lieutenant P. Ferguson, F.R.C.S., R.A.M.C.

The principle is that of the Mackenzie D avidson meth od --namely, that of reconstructing the passage of the rays

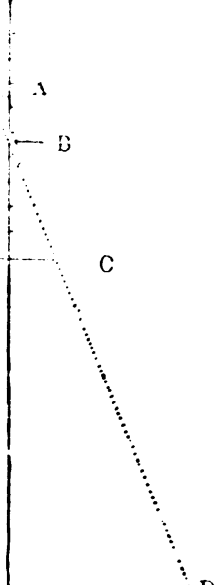
after a deflection of $t$ e tube. The neces sary data are the height of the table from the tube and of the sereen from the table; the amount of the deflection of the tiabe and the amount of movement of the shadow on the screen following the movement of the tube.

The method is as follows: A churt is prepared, and on it is ruled a vertical line about a metre in length. On this line is marked off the height of the table from the tube, which it is convenient to make constant Above this mark a centimetre scale may be set out for con venience in calculation. At the foot of the vertical line another is drawn at rigint angles to it, representing the amount of detlection of the tube. It is convenient to make this constant also - say, $10 \mathrm{~cm}$. long.

D The part is now screened, the foreign A, creen; B, toreign body distinguished, and its position body; $c$, table: $\mathbf{D}$, marked on the skin with an indeliblo tube. pencil. Care has now to be taken that the tube is vertically under the foreign body, and this should be done by careful mersurement. The screen is placed as horizontal as possible on the part, and one edge of the foreign body is marked by means of a metal pointer (that supplied with the Mackenzio Davidson apparatus is very convenient). The tube is now moved a measured distance - sav, $10 \mathrm{~cm}$. 